\title{
Aún es de día, de Miguel Delibes: La instalación metafísica como mecanismo de denuncia social en la ficción
}

\author{
Enrique FERRARI NIETO \\ Universidad de Valladolid \\ eferrari79@gmail.com
}

\begin{abstract}
Sebastián [...] se sintió náufrago y abandonado en medio de aquel océano de humanidad que le envolvía. Era aquél un mar espeso e inextricable, colmado de reconditeces, escollos y arrecifes; un mar difícil, donde suponía un esfuerzo de titanes sostenerse a flote.
\end{abstract}

Miguel Delibes, Aún es de día

\begin{abstract}
RESUMEN
Con el esquema conceptual de la instalación metafísica de Marías, se plantea una nueva lectura del relato de la vida del personaje Sebastián Ferrón como lucha desigual con su circunstancia (en los distintos ámbitos que lo afectan, que se superponen concéntricos), que convierte la novela en una denuncia social implacable de la sociedad española de posguerra. Por lo que, frente a otras ubicaciones para Aún es de día en la narrativa de Delibes, en las que no va más allá de mera tentativa, este trabajo plantea para su segundo libro un nuevo espacio como novela de transición. Por su temática. Porque a pesar de sus limitaciones formales, Delibes esboza por primera vez el grueso de las inquietudes que forjan su literatura, que encajaría, mejor que en el existencialismo cristiano francés con el que la han vinculado, en el ámbito de la antropología metafísica de Julián Marías, que arranca de la razón vital de Ortega y Gasset.
\end{abstract}

Palabras clave: Julián Marías, posguerra española, insolidaridad, circunstancia.

\begin{abstract}
With Marías' conceptual diagram about metaphysical installation, it is possible another interpretation of the Sebastián Ferrón's life, as an unequal fight with his circumstance. It tourns the novel into a social denunciation of Spanish postwar society. Some interpretations for Aún es de dia in the Delibes' narrative consider this novel only as a tentative. However, this study sets it out a new place as a transition novel for its themes. Although its formal faults, Delibes outlines the majority of his literary preoccupations, next to Julián Marías' metaphisycal anthropology (from Ortega y Gasset's vital reason), not to French Christian existentialism.
\end{abstract}


Keywords: Julián Marías, Spanish postwar period, non-solidarity, circumstance.

\section{Sumario}

0.- Introducción. 1.- Aún es de día como novela de transición. 2.- La instalación metafísica: los círculos concéntricos de su denuncia social. 3.- Las implicaciones del héroe/antihéroe en la Castilla de posguerra.

\section{Introducción}

En los intentos por ubicar la resistencia con la que desde 1950 unos pocos jóvenes novelistas se enfrentaron (o dieron la espalda) a los cauces culturales del franquismo, las nóminas más restrictivas han dejado fuera sistemáticamente a Delibes, al menos el de los primeros años, hasta la publicación de novelas como Las ratas, de 1962, que nace empujada por los impedimentos que la censura le pone en su trabajo en la dirección del diario El Norte de Castilla. A diferencia que con las primeras novelas de Rafael Sánchez Ferlosio, Carmen Martín Gaite, Ignacio Aldecoa o Jesús Fernández Santos (que él incluye dentro de su propio grupo, como los niños de la guerra, nacidos en torno a 1920), de sus libros no se ha destacado su crítica social más o menos velada, lastrados quizá (para ser incluidos en este grupo) por su ambiente rural o provinciano, que los colocaba en otros parámetros, más atentos a las relaciones que se tejen entre el individuo y su entorno que a teorías descarnadas sobre las estructuras sociales. Fue un testigo, no un teórico, dice César Alonso de los Ríos ${ }^{1}$. Lejos, además, de los círculos literarios de Madrid y Barcelona. Pero con su segunda novela, la malograda Aún es de día, publicada en 1949, un Delibes todavía balbuciente consigue revelar, dramáticamente, en su sentido más orteguiano, la atmósfera insana, asfixiante, de la posguerra, con el tono demoledor (aunque menos obvio) que constituyen los incesantes intentos del protagonista (hipersensible a cuanto lo rodea) ${ }^{2}$ por ir construyendo una vida digna ante una circunstancia imposible: un escenario de obstáculos, con diferentes rostros, que se convierte en auténtico antagonista cuando el personaje principal decide (a diferencia de Pascual Duarte, por ejemplo) no recorrer el camino que su entorno ha marcado para él. Hasta hacer de la novela una denuncia (la soledad del hombre moderno) encajada en los límites escrupulosos que se impone Delibes como narrador, con la función que él entiende que tiene un novelista: revelar una parcela

\footnotetext{
${ }^{1}$ C. Alonso de los Ríos (1993), p. 36.

${ }^{2}$ M. Delibes (1994), pp. 203-204: «Sus lucubraciones desembocaban siempre, fatalmente, en una prístina conciencia de su absoluto aislamiento. Y, en estos casos, le daba por pensar si no sería, en realidad, un exceso de sensibilidad lo que engendraba todos sus problemas. Él veía a los demás hombres quemar la vida sin detenerse a reflexionar si eran o no comprendidos. Esto les era indiferente».
} 
de la realidad: ir de lo particular a lo universal ${ }^{3}$. Porque, como ha escrito Julián Marías, ambos, el personaje de ficción y el individuo real, son un drama, un relato. Por lo que la novela capaz de entrar en lo más hondo del personaje puede apresar en su forma dramática o narrativa el secreto de la existencia, aunque carezca de un sistema de conceptuación propio ${ }^{4}$; puede intentar una respuesta sobre el sentido de la vida que, desde Ortega, es la complementación de sujeto y circunstancia, del hombre y su entorno.

\section{Aún es de día como novela de transición}

Un poco después de publicar esta segunda novela, Delibes escribe sobre algunos narradores coetáneos suyos. En la ficha de Sánchez Ferlosio se extiende más, porque es su apuesta para la pervivencia de la novela española de posguerra: la de los niños de la guerra ${ }^{5}$. Pero advierte ya de las pocas ganas que tiene Ferlosio de seguir con la ficción. Después de El Jarama decide retirarse. Prefiere -ha preferido desde entonces, de hecho- la gramática, la filología o los ensayos breves a «la literatura en esencia» que, escribe Delibes, «le parece un menester insulso y él no quiere incurrir en él». Porque considera la novela como un quehacer poco serio. Le aburre, dice. Y Delibes, respetuoso, tiene que aceptarlo. Pero su planteamiento es otro, muy lejos del de Ferlosio; aunque, incómodo con el papel de intelectual, apenas lo ha desarrollado teóricamente: Como una alternativa en epistemología a la abstracción, a la teoría. Porque, para él, la novela es un mecanismo único que permite el análisis del entorno desde la retina de los personajes (cuya creación es lo que justifica a la propia novela), como una posibilidad de adoptar una o varias perspectivas diferentes con las que ahondar en el hombre: «Captar la esencia del hombre y apresarla entre las páginas de un libro es la misión del novelista» ${ }^{6}$. Como un modo insustituible de comunicación, que han planteado también otros novelistas importantes del siglo XX: «Ahondar en el hombre y acertar con su última

\footnotetext{
${ }^{3}$ M. Delibes (2004), pp. 132-133: «La universalidad estriba en ahondar en el hombre y acertar con su última diferencia. Alumbrar el pedazo del mundo que le ha caído en suerte es la más noble tarea del novelista.»»

${ }^{4}$ J. Marías (1959), p. 119.

${ }^{5}$ M. Delibes (2004), pp. 73-80.

${ }^{6}$ Escribe en «Los personajes en la novela», La Vanguardia 20-XII-1980, p. 5: «Crear tipos vivos, he aquí el principal deber del novelista. Unos personajes que vivan de verdad pueden hacer verosímil un absurdo argumento, relegar, hasta diluir su importancia, la arquitectura novelesca y hacer del estilo un vehículo expositivo cuya existencia apenas se perciba. Poner en pie unos personajes de carne y hueso e infundirles aliento a lo largo de doscientas páginas es, creo yo, la operación más importante de cuantas el novelista realiza [...] Visto desde este ángulo, el personaje se convierte en eje de la novela y su carácter prioritario se manifiesta desde el momento en que el resto de los elementos que integran la ficción deben plegarse a sus exigencias.»
} 
diferencia» ${ }^{7}$. Que se muestra con la continuación en la ficción de aquellas alternativas que no se pudieron desarrollar en una vida real, con la invención de lo que hubiera sido esa vida si se hubiera tomado otra opción que un momento dado se desdeñó. Lo que advierte Kundera en La insoportable levedad del ser: que la novela no es una confesión del autor, sino una exploración de lo que es la vida humana: de la existencia como un campo de posibilidades. Con una capacidad cognitiva única: «Esos novelistas descubren lo que solamente una novela puede descubrir: demuestran cómo, en las condiciones de las paradojas terminales, todas las categorías existenciales cambian de pronto de sentido» ${ }^{8}$. Como una larga interrogación, dice el escritor checo, a partir de unos personajes que no son simulacros de seres vivientes, sino egos experimentales ante una situación de paradojas terminales en un mundo autónomo, el de la ficción literaria, en el que la relación entre la ficción y la realidad vital del lector no tiene un carácter normativo ${ }^{9}$. Un intento de explicar la realidad a partir de la creación de nuevas posibilidades teóricas que viven los personajes de la ficción, que en su desarrollo en la novela pueden desentrañar nuevos rincones de la existencia. El instrumento capital del hallazgo de la persona, el punto de partida para aprehenderla, afirma Julián Marías. ${ }^{10}$ Como una alternativa a la propia vida, pero con los mismos mecanismos: como la posibilidad de decidir uno mismo un futuro, o unas decisiones futuras que tienen que encajar en una circunstancia determinada. Con una función en primer lugar epistemológica, para intentar explicar con las vidas ficticias los entresijos de la existencia: lo que ha buscado la novela del siglo XX frente a la anterior, que tenía una función más lúdica ${ }^{11}$. Porque esa construcción, que debe ser-decía Aristóteles, decía Cervantes- verosímil, anticipa, sin los conceptos, una razón narrativa, la del existencialismo o el raciovitalismo: la razón construyéndose en la existencia: una razón dinámica (que reconstruya la fluencia de la vida, escribe Marías) ${ }^{12}$ que se va forjando al tiempo que es reclamada desde fuera, como respuesta, atenta a los estímulos, y no cerrada en sí misma: dramática, diría Ortega. Como el «Caminante, no hay camino, se hace camino al andar» de Machado, porque cada individuo es novelista de sí mismo: cada uno tiene que escribir su propio futuro. Como la intuición desasosegada del señor Ferrón: «Sebastián recordaba haber sorprendido varias veces a su padre llorando. Sabía Sebastián que lloraba por él, previendo la amargura del camino que aún le quedaba por recorrer y presintiendo,

\footnotetext{
${ }^{7}$ M. Delibes (2004), pp. 131-132.

${ }^{8}$ M. Kundera (1987), p. 22.

${ }^{9}$ M. Kundera (1987), pp. 42-45.

${ }^{10}$ J. Marías (1997), p. 82.

${ }^{11}$ M. Delibes (1985), p. 103.

12 J. Marías (1997), pp. 65-66.
} 
proféticamente, que él, su padre, tan débil, no podría acompañarlo mucho tiempo. Y así fue» ${ }^{13}$.

Con El camino, que publica solo un año después, Delibes ya es capaz de dar vida a sus personajes, y construir una atmósfera con los tres pilares que le exige a la novela: un hombre (un personaje), un paisaje (un ambiente) y una pasión (un móvil). Con los dos intentos anteriores -como ha reconocido él mismo- no pudo: quedan encorsetados, demasiado atada la narración a la tesis final, anquilosados los personajes y sus acciones, sin acertar con su escorzo: «Venían a representar los ejercicios primerizos de un aspirante a escritor y, como tales, unas obras de tanteo y exploración escritas para ser destruidas. De ahí que me resista a considerar estas obras, toscas e inmaduras, como la primera etapa de mi quehacer narrativo, a no ser que merezca la consideración de etapa el periodo del despertar, el aprendizaje y los coscorrones» ${ }^{14}$. Delibes acierta cuando en él se impone el observador sobre el teórico. Pero Aún es de día -precisamente por esas limitaciones que tiene como novela- permite, mejor que otras más corales, ver desnudos los principios básicos existenciales que van a ser (sin el entramado conceptual) una constante en su narrativa posterior, encarnados ya en la ficción. Porque sin dar -con el término de Bajtin- con una polifonía adecuada para armar una atmósfera más consistente, limita básicamente la narración a la trayectoria vital del personaje de Sebastián Ferrón; pero así puede volcarse en los efectos devastadores de ese entorno hostil en el individuo que, a pesar de su firme voluntad de prosperar socialmente, es incapaz de superar tantos obstáculos.

Es su novela de transición. Por su temática. Con la que comienza a armar sus inquietudes. Porque la primera, La sombra del ciprés es alargada, se centra (con una fijación que ahoga la novela) en la muerte: el tema que tiene desde niño en la cabeza y que, según él mismo ha comentado, le empuja a escribir por primera vez. Una vez desahogada su obsesión, para la segunda novela acumula ya los nuevos temas en torno al hombre y a su medio y las coordenadas estéticas que van a perfilar el resto de su obra: El desamor, la falta de solidaridad entre los hombres (la violencia, la crueldad, la indiferencia, la soledad o el egoísmo) ${ }^{15}$ de la que caen víctimas muchos de sus personajes. Temas que aquí están desnudos. Solo el soporte, con unas pocas pinceladas, convertidas luego - no todas- en ideas matrices de su narrativa, que se van desprendiendo del propio transcurrir vital del protagonista (con su respuesta honrada frente a las parrafadas demagógicas del Sixto, hermano de la Aurora) ${ }^{16}$ al margen de esa solución final en la que Delibes

\footnotetext{
${ }^{13}$ M. Delibes (1994), p. 27.

${ }^{14}$ M. Delibes (2004), p. 160.

${ }^{15}$ Cf. J. Rodríguez (1989), p. 134.

${ }^{16}$ M. Delibes (1994), p. 119. Le dice el Sixto a Sebastián: «No comprenderé nunca vuestra abulia para acomodaros a tirar por un sendero que otro traza. Es una esclavitud idiota la
} 
parece querer redimir al personaje por su fe, por su religiosidad, para cerrar la novela, poniendo más énfasis en los resultados, fracasos todos, que en las motivaciones, en su voluntad firme de remar contracorriente ${ }^{17}$, y de levantarse después de cada caída, esperanzado a pesar de los resultados: voluntad a la que, después de todo, hace referencia el título definitivo de la novela (frente al primero que pensó: Barro vivo). Escribe con ese isomorfismo inevitable entre el transcurrir vital de Sebastián y el general de los españoles de posguerra: "Cada día se despertaba uno con una nueva ilusión y cada noche la ilusión se trocaba en un amargo desengaño» ${ }^{18}$. Una vitalidad que Delibes enfrenta a la de Orencia, su hermana, para caracterizar al protagonista. De Sebastián escribe: «Veinte años llevaba pensando, cada mañana, al despertar, que aquel día podría traerle un cambio radical en su existencia» ${ }^{19}$. Y de Orencia, tremendamente escéptica a pesar de su edad: «Cruzaba la vida con una frialdad glacial, impropia de sus pocos años $»^{20}$. Del argumento de la novela tiran luego demasiado los arneses de la educación o formación religiosa de Sebastián, muy básica, que encorsetan el desenlace. Pero la intuición primera (que hace del alma un símbolo de la conciencia del individuo de su propia autonomía, o como última puntualización del deseo de una autonomía personal, y no como un querer evadirse de lo terrenal: tentación que desecha al instante), y los desarrollos puntuales de esa intuición, de esa conciencia del narrador de la naturaleza solidaria y menesterosa del ser humano, abren otra posible lectura (detrás de la más obvia) coetánea, en 1949, a las principales propuestas de la filosofía existenciaria (o existencial, si no acotamos el término para la filosofía francesa de mediados del XX).

La vida, escribe Ortega y Gasset, no puede reducirse a simple biología. Con el hombre, la vida es más bien biografía, más allá de lo puramente biológico: una faena que cada uno tiene que ejecutar. Porque vivir, dice, es ser fuera de sí, realizarse en su lucha con las cosas, oprimiendo la circunstancia para alojarse en ella, en un dinamismo dramático entre el mundo y el yo (que es solo el primer «yo» del «yo soy yo y mi circunstancia», el «yo» del idealismo, de la tentación del idealismo, dice Marías, que cosifica a la persona). Circunstancia y vocación. Y también azar, como el elemento irracional. Pero la autenticidad de la vida de cada hombre la determina su fidelidad a su vocación, entendida como el programa íntegro e individual de la existencia. Mi yo es mi vocación. Y mi mundo el

vuestra, ¿no? Y no es lo peor el trabajo, sino la rutina de todos los días; dando siempre la misma vuelta, como si el hombre no fuese un poco más que una máquina de rallar pan...»

${ }^{17}$ M. Delibes (1994), p. 306. Escribe al final de la novela: «Era tedioso bracear contra corriente, y Sebastián se veía obligado a desarrollar un violento esfuerzo físico para conseguirlo».

${ }^{18}$ M. Delibes (1994), p. 233.

${ }^{19}$ M. Delibes (1994), p. 9.

${ }^{20}$ M. Delibes (1994), p. 11. 
repertorio de mis posibilidades vitales, lo que puedo ser, mi potencialidad vital. Porque el hombre -al contrario de lo que pensaba la ontología tradicional- es el ente que se hace a sí mismo. Como si fuera el novelista de su propia vida, a la fuerza libre, porque carece de identidad constitutiva. La vida, sigue Ortega, es drama. Es un tener que írsela cada cual haciendo en una perpetua tensión, en una lucha constante por llegar a ser lo que tengo que ser. Lo que señala Marías en su Antropología metafísica: a la persona la constituye su capacidad de crearse un programa, un proyecto de futuro. Porque la persona no está ahí, como si fuera una cosa, sino que está viniendo. Porque tiene la mirada en el futuro, en lo que aún no es, pero será: una realidad que no puede ser material (el hombre está en el presente, no en el futuro, que no existe), pero desde la que vive, como futurizo: vivimos, dice Marías, primariamente en el futuro. Indigentes, menesterosos. Yo soy presente, pero orientado al futuro, que es irreal, pero que le confiere a este mundo real, del presente, su mundanidad, su carácter de mundo. Con lo que el yo, superado el idealismo, es esa condición programática y viniente, en la que el yo pasado no es el yo, sino una circunstancia en la que me encuentro, porque en la persona hay mismidad, pero no identidad. Y vida, entonces, la organización real de la realidad. Con lo que -vuelve Ortega- el héroe, con un sentido más ceñido, es aquel que está decidido a no contentarse con la realidad: el que se niega a repetir los gestos, porque quiere asentar en sí mismo el origen de sus actos, resistiéndose al hábito.

De Aún es de día no ha habido más interpretación que una vaga referencia a su condición de novela existencial cristiana, con valores como la esperanza o la resignación o el amor al prójimo, con su contrario: la indiferencia y la crueldad ${ }^{21}$. Conformando la etapa negativa de Delibes, junto a La sombra del ciprés es alargada, en la clasificación de Ramón Buckley: en las que el protagonista se enfrenta a la sociedad y defiende una individualidad que esta trata de arrebatarle. $\mathrm{O}$ como ejercicio de conocimiento de la condición humana, también con El camino, en la clasificación de Sobejano ${ }^{22}$. Cercana, por tanto, al pensamiento de Gabriel Marcel. Aunque es improbable que Delibes lo conociera entonces ${ }^{23}$. O a Baroja, a su Andrés Hurtado, para el que la vida también es sufrimiento y lo mejor es quedarse a un lado. $\mathrm{O}$ a Camus, y su extranjero, también antiheroico. Pero, si se perfilan (y reinterpretan) las vaguedades con las que Sebastián, muy limitado intelectualmente, alude al alma (el elemento principal que ha empujado a esos pocos trabajos a vincularlo con el existencialismo cristiano), puede encajar, como

${ }^{21}$ M. Delibes (1994), p. 122. Escribe: «Hasta entonces no advirtió Sebastián lo incompleto de las satisfacciones humanas; la necesidad cruel de arruinar a un prójimo para encumbrar la propia existencia. La alegría de un hombre se cimentaba en el dolor y el aniquilamiento de otro.»

${ }^{22}$ Cf. J. Rodríguez (1989), p. 42.

${ }^{23}$ En los números 31 (3 de junio de 1949) y 72 (3 de diciembre de 1950) de La Hora se reproducen dos artículos de Gabriel Marcel. Cf. J. Gracia (2006), p. 132. 
exploración de la existencia (desde la conciencia de su autonomía frente al torrente social), en una estructura filosófica más sólida, a partir del concepto de instalación, de Marías, que potencia la justificación estética que se da Delibes con el análisis de un temple de mínimos, como imagen especular de su sociedad, que encauza bien el protagonista, con ese punto álgido que es su enamoramiento de la Aurora (en realidad, «un anómalo y vago sentimiento, mezcla de compasión y desconocida ternura», frente a la pasión que le despierta un maniquí) ${ }^{24}$, hasta su radical desorientación tras perder definitivamente el equilibrio ${ }^{25}$. Porque la denuncia de la miseria del campo o de Castilla que hay detrás de la narrativa de Delibes (su gran vórtice) se fundamenta ontológicamente en la resistencia insalvable que supone para cualquier desarrollo vital digno la instalación lamentable del protagonista: como punto de partida que, inevitablemente, a pesar de algunas falsas ilusiones, le va a impedir cualquier progreso social significativo, en lo que se vuelve una y otra vez en la trama, sin sutilezas argumentales ni personajes hondos que revistan su maniqueísmo. Muy próximo a la teoría de la propina de la que escribe Josep Pla: a las expectativas vitales de los hombres de campo, que parten del supuesto de que vivimos en el peor de los mundos posibles, frente a lo que se cree el Cándido de Voltaire, con lo que todo lo que pueda llegar de más es solo una propina del destino. Mejor, dicen ( $\mathrm{y}$ dice el propio Pla), resignarse a un valle de lágrimas corregido por un sistema de propinas que pensar en el mejor mundo posible y enrabietarse con cada percance. Y cerca, también, de lo que piensa Andrea, la protagonista de Nada, de Carmen Laforet: «Que cualquier alegría de mi vida tenía que compensarla algo desagradable. Que quizá esto era una ley fatal» ${ }^{26}$.

El compromiso social (la preocupación por el prójimo, dice él) ${ }^{27}$ de la narrativa de Delibes no está solo en unas pocas ficciones desde Las ratas, publicada quince años después de su primera novela, con esa genealogía que arranca con las limitaciones que le imponen en El Norte de Castilla para informar de la realidad del campo castellano. Es, desde el comienzo, uno de los pilares de su pensamiento literario, en tanto que se propone explicar la condición del hombre, que él busca escorado en la sociedad: «La misión del novelista», escribe, «consiste en descifrar

\footnotetext{
${ }^{24}$ M. Delibes (1994), p. 57.

${ }^{25}$ De hecho, Marcel, tras publicarse Introducción a la Filosofía, advierte de la importancia de la observación de Marías sobre la peculiaridad de la vida del hombre respecto a la de los demás animales. Cf. G. Marcel (1971), p. 75.

${ }^{26}$ C. Laforet (2007), p. 123.

${ }^{27}$ M. Delibes y J. Vergés (2002), p. 285. Escribe: «Para el tercer volumen de $O$. C. estoy preparando Aún es de día, La hoja roja y Las ratas. La agrupación viene dictada por la preocupación por el prójimo -social se dice desde Marx- que acompaña a mis novelas. De este modo el prólogo puede responder a una unidad y el volumen encierra cierta armonía temática.»
} 
al hombre ${ }^{28}$. Para superar la interpretación esteticista que los del 98 hacen de Castilla $^{29}$. Con lo que Aún es de día revela también -nítidamente si se la apuntala con las claves antropológicas de Marías- una crítica social demoledora a través de la inclusión de unos ámbitos en otros (su propio cuerpo, su hogar, con su madre y su hermana, su barrio, su ciudad y, por último, la España de la posguerra), como círculos concéntricos que crecen todos desde la noción de la instalación metafísica, como escenarios, en las coordenadas de la filosofía mundana de Ortega, como circunstancias que son una suma de impedimentos. Un diagnóstico más contundente que el de otras novelas decididamente derrotistas, porque en esta el personaje no se rinde, pero, aún así, no es capaz de dar los pasos definitivos. Así, Delibes, de la mano de Destino y de Vergés, se incorpora muy pronto a esa cultura emergente de los primeros cincuenta que es crítica con la realidad española de su tiempo; pero sin ser mostrenca, como ha escrito Jordi Gracia en su Estado y cultura: con la misma intencionalidad que la novela social, pero con nuevas armas y técnicas, plenamente modernas, con las que estos jóvenes (Delibes no ha cumplido entonces 30 años) muestran su desazón moral y su actitud inconformista y de protesta ${ }^{30}$. Quizá menos ruidosos que los anteriores, pero con una voluntad firme de no tragar ante la presión oficial $^{31}$.

\section{La instalación metafísica: los círculos concéntricos de su denuncia social}

En 1925, Francisco Ayala, con su Tragicomedia de un hombre sin espiritu, exprime también (más orteguiano que Delibes) el contenido ontológico de la idea de «instalación» con el desarrollo semántico de la expresión popular de que el hábito hace al monje: «El hábito sí hace al monje en que convierte su novela: el hábito, estrictamente; el hábito, dándole un significado más amplio» ${ }^{32}$. Su historia es la dura vida de un joven que, como Sebastián, tiene una malformación física (también es jorobado) que lo instala en el mundo (con la primera de las instalaciones posibles, la corporal) en condiciones poco ventajosas: «Su figura contrahecha le hizo retraído y huraño; sufrió....»33. Con un punto de partida complicado, porque le supone, de entrada, el rechazo social de su entorno, que

\footnotetext{
${ }^{28}$ M. Delibes ( 2004), p. 130.

${ }^{29}$ C. Alonso de los Ríos (1983), p. 180. Señala Delibes: «La atracción de Castilla sobre los del 98 es un fenómeno interesante y explicable. Estos señores encontraron en la pobreza de Castilla la manifestación del problema español. [...] Todos ellos hicieron una interpretación estética de Castilla más que sociológica. De manera que si la orientación hacia Castilla de estos señores me interesa, no me valen sus planteamientos de los problemas. Nunca encontrarán un análisis socioeconómico en ninguno de ellos.»

${ }^{30}$ J. Gracia (2006), p. 286.

${ }^{31}$ Cf. M. Delibes y J. Vergés (2002), pp. 142, 148, 259, 284, y 306.

${ }^{32}$ F. Ayala (1993), p. 28.

${ }^{33}$ F. Ayala, (1993), p. 21.
} 
también tiene que vencer. Y, por esto, una mayor introspección, un encerrarse en sí mismo, al sentirse diferente, poco integrado ${ }^{34}$, y la tentación de una evasión espiritual que olvide al cuerpo, huyendo de Madrid. Aunque el relato de Ayala es menos gris que el de Delibes, al estar más enfocado al enredo (frente a la acción mínima de Aún es de día), como si fuera un entremés, casi una pieza jocosa con el imprevisto del extraño enamoramiento que altera un vivir blando y amable, de modorra espiritual, con un personaje que Ayala dibuja decididamente estrafalario, y a gusto con su soledad ${ }^{35}$, sin esa ambición social de Sebastián, en un ambiente también pintoresco, de principios del XX, pero con la deuda del narrador a la mirada de los autores del siglo XVII. Porque la atmósfera de la novela de Delibes es la de Nada, de Carmen Laforet, o la de La familia de Pascual Duarte, de Cela (al margen de la intención que pudo tener Cela al escribirla); no esta. Aunque el final es parecido: una fugaz impresión de que pueden reconducir sus vidas (al encontrar, primero, trabajo, o mejorarlo), e integrarse en la sociedad, con el punto álgido de creerse queridos, hasta el descubrimiento de la burla (con Miguel, solo para divertirse una señora ociosa y sus doncellas) o el engaño (más grave con Sebastián). Pero Ayala, con una estructura narrativa más audaz que la de Delibes, se permite (con dos amigos lejanos del protagonista, uno de ellos el narrador, que han encontrado el manuscrito) los comentarios que interpretan desde fuera la vida de Miguel Castillejo como tarea (fallida). Hablan entre ellos, en la habitación vacía de Castillejo: «Miguel no tiene la culpa de que su vida, que es su obra, sea absurda, desagradable y disparatada». «Fue un escultor que al terminar una estatua de Venus se retira para contemplarla en conjunto y ve que ha hecho un monstruo, un monstruo con algunas bellezas, desde luego...» ${ }^{36}$. Con lo que pone a la vista el puente -con el que arma su novela- que levantó Ortega entre Cervantes y su ética para recuperar esa intuición de la vida como proyecto (cuando le dice don Quijote a Sancho que no hay posada más divertida que el camino), en sintonía con la nueva línea tangencial que abren las filosofías existenciales, para las que la experiencia, lejos de ser un registro pasivo, tiene una naturaleza activa e, incluso, como ha señalado Gabriel Marcel, dialéctica, que requiere varios niveles de reflexión. Le dicen a Miguel: «Lo que necesitas es curarte esa pasión de ánimo que tienes, y como únicamente lo puedes hacer es rompiendo los moldes de tu vida prevista; luchando con las circunstancias; solucionando un conflicto a cada paso -pero sin

\footnotetext{
${ }^{34}$ F. Ayala (1993), p. 21: «El dolor, señor mío, hace que el pensamiento se refugie en el recinto de sí mismo, y enamorado de su grandeza olvide las ingratas impresiones de fuera». ${ }^{35}$ F. Ayala (1993), p. 57: «No desconocía nuestro hombre que su persona era desagradable a la vista, por más familiarizado que estuviera con ella, pero no por eso dejaba de hacer lo que le venía en gana, sin ocuparse del prójimo. Al principio le daba vergüenza y cortedad el salir solo, pero poco a poco se fue acostumbrando y ya nada le importaba la gente que pasaba por su lado, ni hacía cuenta de sus miradas, palabras y gestos, resignado con su suerte.»

${ }^{36}$ F. Ayala (1993), p. 20.
} 
darle categoría de preocupación absorbente, porque entonces todo será perdido» ${ }^{37}$. Lo que escribe Marcel: «Se trata no solo del fin hacia el cual nuestra vida se ordena, sino más bien del combustible mental que nos permite continuar» ${ }^{38}$.

Aún es de día es el testimonio amargo de la lucha desigual de dos elementos que tiran uno contra otro para conformar al individuo, que en la narrativa de Delibes es el débil, el marginado: el entorno, en un extremo de la cuerda, que determina las posibilidades reales de progreso del individuo, y la voluntad del personaje, en el otro extremo, que no le permite salirse del cauce que ya le ha trazado ese entorno hostil. Delibes, sin dispersarse en otras historias, va marcando morosamente los pasos del giro completo que, en solo unos meses, da la vida de Sebastián. Con su empeño, primero, por mejorar las condiciones miserables en que viven él y su familia, con resultados esperanzadores, que al menos apuntan a la posibilidad de dar un salto a un nuevo nivel social y económico, con su trabajo en los almacenes Suárez y luego con su noviazgo con Aurora; para volver, inmediatamente después, al punto de partida, hundido por su entorno social y familiar, con otro giro con el que deshacen esos pasos previos, al saberse engañado, hasta quedarse sin trabajo y sin novia. Sebastián funciona como homo viator, lo que hace posible conceptualizar las intuiciones del libro a partir de las filosofías de Ortega y de Marías, pero la novela merodea continuamente sus orígenes, como una cadena que no permitiría cumplir con el trayecto, con sus ámbitos familiar y social como círculos concéntricos que lo abarcan todo, para mostrar insistentemente la imposibilidad de salirse de ellos. Escribe: «A Sebastián le dolía ver cómo pasaban los años sin que su personalidad aumentase por ello; le mortificaba que en todas partes le considerasen como un chiquillo, sin pizca de poder de representación ${ }^{39}$. A lo que responde también el concepto de instalación, que en las primeras páginas son descripciones tremendistas, que vinculan la historia de Sebastián con la del Pascual Duarte de $\mathrm{Cela}^{40}$, focalizadas sobre todo en la madre, como influencia negativa, que coarta la voluntad del protagonista, recordándole constantemente sus limitaciones: «Temía, más que nada, aquella lengua de su madre que le zahería sin compasión, embistiendo siempre a los puntos más vulnerables y sensibles», o: «Le dolían sus frases, se le clavaban como dardos, muy adentro, en un lugar inlocalizable», o: «Le desazonaba a Sebastián esta inmediata fiscalización de su madre, esta constante vigilancia para aquilatar sus defectos y cada uno de sus descuidos» ${ }^{41}$. Como el primero de los círculos hechos de circunstancias adversas, al que se suman su tara física, su barrio, pobre y violento, y la España deprimida y hambrienta de los años 40, para hacer de su instalación metafísica, en cada nivel de su circunstancia, un

\footnotetext{
${ }^{37}$ F. Ayala (1993), p. 153.

${ }^{38}$ G. Marcel (1971), p. 76.

${ }^{39}$ M. Delibes (1994), pp. 47-48.

${ }^{40}$ Cf. P. de la Puente Samaniego (1986), p. 40.

${ }^{41}$ M. Delibes (1994), pp. 13-15.
} 
aglomerado de trabas para su objetivo, que él entiende como el descubrimiento del alma, o de la conciencia de tenerla, que, con la recomposición de sus notas, no tendría una dimensión religiosa honda, pero sí intuye como un proyecto, con lo que la vida no sería ya una cosa -su cuerpo deforme, al que hace responsable de sus miserias- sino un proyecto personal marcado por la autonomía del alma, por la conciencia del dominio sobre su propia vida, de controlar él, por fin, la situación.

La motivación final de Sebastián y las intuiciones de la novela no se entienden entre sí: Él considera que casarse con la Aurora es el sacrificio auténtico, incontaminado, el acto meritorio y trascendente que, en su día, tendría una eterna contraprestación. Sabe que no va a ser entendido en el barrio, que pensarán que lo hace por el dinero, pero, desde esa creencia cristiana suya de un alma separada del cuerpo, olvida los modos sociales para centrarse en su salvación eterna. Pero las intuiciones, que no engendrarían esa respuesta final, construyen el argumento de la novela como una transformación vital del protagonista a partir de su conciencia de la vida como proyecto trazado por uno mismo en la circunstancia (que no pierde al final, aunque los motivos sean otros) a partir de la autonomía que siente al reencontrarse con su alma, frente a ese verse arrastrado que había fundamentado su vida hasta entonces. Entendiendo el yo como condición programática. Por lo que, una vez redescubierta el alma, supera y desecha esa primera tentativa de evasión con la religión, de rendirse, de buscar la ataraxia, porque percibe -otra vez orteguiano, y no místico- que tiene una tarea última: casarse con la Aurora para hacerse cargo del niño que esta espera.

En la dicotomía básica de cuerpo y alma que retoma Delibes como elementos del proyecto de Sebastián (muy clara en el primer título que pensó: Barro vivo) ${ }^{42}$, el alma marca la autonomía y el cuerpo el entorno (como encarnación del sujeto), que funciona aquí solo como resistencia. Frente al personaje que se sabe determinado por el ambiente y se deja llevar, como Pascual Duarte, la biografía de Sebastián es la suma de pasos, de pasitos, para mejorar las condiciones de las que parte con una voluntad fuerte que tiene que enfrentarse continuamente a las otras voces de su entorno, especialmente la su madre. Otras novelas de posguerra también plasman con la ficción esa impresión de que es imposible superar los condicionantes ambientales, con la justificación o la confesión del protagonista muchas veces desde el tremendismo. Pero lo hacen convencidos desdela primera línea, sin darle al personaje la oportunidad de que insista en desmarcarse del camino más obvio. Sentenciado desde el principio. En la carta en la que descarga su conciencia tras ser condenado a muerte, Pascual Duarte escribe para justificarse: «Yo, señor, no soy malo, aunque no me faltarían motivos para serlo. Los mismos cueros tenemos todos

${ }^{42}$ Cf. M. Delibes y J. Vergés (2002), pp. 62-63. Sobre las dudas con el título de la novela: la primera propuesta de Delibes fue Barro vivo, que no gustó en la editorial. Propuso también, sin convencerle del todo, El amanecer, Un pobre hombre o Días oscuros e incluso Todos somos de barro, hasta dar con el definitivo. 
los mortales al nacer y sin embargo, cuando vamos creciendo, el destino se complace en variarnos como si fuésemos de cera y en destinarnos por sendas diferentes al mismo fin: la muerte. Hay hombres a quienes se les ordena marchar por el camino de las flores, y hombres a quienes se les manda tirar por el camino de los cardos y de las chumberas. Aquellos gozan de un mirar sereno y al aroma de su felicidad sonríen con la cara del inocente; estos otros sufren del sol violento de la llanura y arrugan el ceño como las alimañas por defenderse. Hay mucha diferencia entre adornarse las carnes con arrebol y colonia, y hacerlo con tatuajes que después nadie ha de borrar ya» ${ }^{43}$. Que es la misma impresión a la que llega el lector de Aún es de día, pero con la convicción, esta vez, de haber intentado realmente desmarcarse el protagonista, de haber querido ser dueño de su destino y no haberlo conseguido. De tener la certeza de que, haga lo que haga (porque de hecho lo hace), no va a poder ir más allá de las posibilidades tan limitadas de su instalación, que dice Marías- es eminentemente corpórea: la de un cuerpo deforme que funciona como símbolo, como el último de los círculos concéntricos que son las resistencias para el desarrollo del individuo en un entorno hostil. Como si Miguel Delibes trabajara desde el isomorfismo entre Sebastián y la España de los años 40: la que está al fondo también en Nada, con la que Carmen Laforet ganó un año antes que Delibes la primera edición del Nadal: esa atmósfera opresiva, sofocante y angustiosa, que en un determinado momento se le puede hacer más soportable al sujeto, ante la aparición de un nuevo elemento liberador (Andrea encuentra a Ena, una compañera de la Universidad ${ }^{44}$, como Sebastián encuentra -o reencuentra, cuando se cree cortejado- a Aurora), pero que no va más allá de un espejismo que no tarda mucho en revelarse como ta ${ }^{45}$, y en devolverle al personaje la cara más dura de la realidad («la vida rompió delante de mis ojos todos sus pudores y apareció desnuda, gritando intimidades tristes, que para mí eran solo espantosas» ${ }^{46}$.

Con la terminología de Julián Marías, las formas de instalación de Sebastián, que van encajándose unas dentro de otras, como ámbitos que forman parte de otros ámbitos más amplios, dibujan en la novela de Delibes la atmósfera más lúgubre para describir la España de posguerra: lo que repiten otros libros de coetáneos suyos como escenario, pero aquí con un papel antagonista más fuerte. Como las reglas imposibles de un juego con el que Sebastián intenta inútilmente forjar su vida. Como una correa muy corta que limita tremendamente sus movimientos. La vida,

\footnotetext{
${ }^{43}$ C. J. Cela (1983), p. 21.

${ }^{44}$ C. Laforet (2007), p. 163: «Pensé que realmente estaba comenzando para mí un nuevo renacer, que era aquella la época más feliz de mi vida, ya que nunca había tenido una amiga con quien me compenetrara tanto, ni esta magnífica independencia de que disfrutaba.»

45 C. Laforet (2007), p. 223: «El amor de ellos [de Ena y su novio, Jaime] me había iluminado el sentido de la existencia, solo por el hecho de existir. Ahora me consideraba amargamente defraudada».

${ }^{46}$ C. Laforet (2007), p. 236.
} 
decía Ortega, es un proyecto, un mirar hacia delante desde una instalación concreta que es, en primer lugar, corpórea, con una condición biológica, dice Marías, que queda afectada por una serie de limitaciones que, con Sebastián, con su «horrenda presencia física ${ }^{47}$, Delibes lleva al extremo para construir los rasgos del escenario de su vida: La primera dificultad es la física, su propio cuerpo, que tiene inmediatamente unas repercusiones sociales, agravadas por su pobreza. Aún así, su vida, desde esos mínimos, transcurre con cierta estabilidad, en equilibrio, o más bien con el paso discreto de un equilibrio a otro («El estado de ánimo de Sebastián oscilaba como un péndulo. Ni él mismo hubiera acertado a definirse»») ${ }^{48}$, al comienzo de la novela con una progresión clara, que responde al esfuerzo de Sebastián por avanzar socialmente venciendo los reparos de su entorno, con el cambio de trabajo desde recadero de la tienda de ultramarinos del señor Sixto (el padre de Aurora, que sirve de paradigma del explotador $)^{49}$ a dependiente de los Almacenes Suárez; y más tarde con su noviazgo con Aurora, con lo que la convierte también en su proyecto, que va asimilando poco a poco. Es el temple sobre el que reflexiona Marías, que aquí funciona como clave interpretativa de la crítica implícita en Aún es de día: la modulación de la instalación del sujeto, que queda encauzada por la sociedad en la que vive ${ }^{50}$. Delibes, que parte la novela en dos, altera completamente la vida del protagonista a partir de un hecho anecdótico: la rotura de la luna de un escaparate en la borrachera con la que celebraba Sebastián su ascenso con sus compañeros. De pronto se desvanece el espejismo y vuelve a estar solo y burlado: la luna la ha roto uno de sus compañeros, pero las culpas recaen sobre él y lo dejan solo: él mismo percibe que no ha dejado de estar solo ni un momento. La misma estructura que se repetirá después, al desvelársele, a él el último, el embarazo de Aurora y su estratagema para que sea él quien cargue con el crío que otro, Benjamín Conde, que muere acuchillado por el hermano de Aurora, no ha querido reconocer. Dos golpes iniciales que inician su radical desorientación, la pérdida del equilibrio, que se consuma definitivamente con la pérdida de su empleo tras una escena patética en la que un Sebastián fetichista se queda (y es sorprendido) con el guante que ha olvidado en los almacenes Irene, una cliente de la que está platónicamente enamorado: «Se tapó los oídos con las manos deformadas y echó a correr enloquecido hacia la puerta. Los denuestos y las negativas de sus compañeros le perseguían como sabuesos ávidos de sangre» ${ }^{51}$. Hasta esa escena final en la que vuelve a ese equilibrio inestable de su vida al reconstruir su

\footnotetext{
${ }^{47}$ Miguel Delibes, Aún es de día, p. 23.

${ }^{48}$ M. Delibes, Aún es de día, p. 65.

${ }^{49}$ M. Delibes, Aún es de día, p. 71. Escribe: «El insensato olvidaba que su bolsa se henchía a costa de los glóbulos rojos del barrio.»

${ }^{50}$ J. Marías (1970), pp. 235-238.

${ }^{51}$ M. Delibes (1994), p. 303.
} 
proyecto, sus objetivos inmediatos, pero otra vez solo y marginado: «Sobre el fondo de aquella algarabía apenas sí se oyó el desgarrado sollozo de Sebastián» ${ }^{52}$.

\section{Las implicaciones del héroe/antihéroe en la Castilla de posguerra}

Delibes busca en el antihéroe, el que se maneja en los márgenes de la sociedad, los rasgos con los que dar una definición del hombre, desde sus imperfecciones. En sintonía, dice él mismo, con la novela contemporánea, que ha cambiado al héroe inmaculado por el pícaro, o por el heredero del pícaro, para criticar a la sociedad, porque el novelista ya no quiere un arquetipo, alguien ejemplar, sino un ser defectuoso $^{53}$. Porque el binomio héroe-antihéroe lo tiene que llevar a otra dicotomía a partir de la instalación del individuo en su circunstancia: como acomodo, en un entorno hospitalario en el que encajaría perfectamente, o -en el que se maneja élcomo incomodidad, a disgusto, fastidiado, lo que permitiría un desarrollo narrativo mayor, con más matices para las digresiones en ese isomorfismo con la realidad imperfecta de Castilla, con la que no caben unos personajes perfectos, cómodos en esa circunstancia. Escribe Marías que cada persona ejerce una presión sobre su circunstancia, y se proyecta con mayor o menor energía sobre lo que la rodea ${ }^{54}$. Los personajes de Delibes son en su mayoría desgraciados en conflicto con la sociedad: marginados que son incapaces de realizarse como individuos, incapaces de hacer presión alguna en su circunstancia. En parte -como señaló hace tiempo Ramona F. del Valle Spinka- porque esa sociedad (los compañeros de trabajo de Miguel, o su madre, o su novia, por ejemplo) no pone ningún interés en ayudarlos ${ }^{55}$. Como escribe Delibes: «Sebastián experimentó una sutil congoja al percatarse de la extremada facilidad que encuentran los hombres para asociarse contra el débil ${ }^{56}$.

Pero, al apuntalar Aún es de día con la antropología metafísica de Julián Marías, aparece detrás la noción orteguiana de «héroe», de la que arranca también Marías, que atiende otros rasgos que los del significado que le da Delibes, con un campo semántico que destacaría, más bien, su voluntad de alterar su circunstancia preestablecida. Para Delibes el héroe literario, el héroe épico, arquetípico, es el apuesto y valiente, el defensor del honor, la mujer y los débiles, inteligente, generoso, atractivo e inmaculado, sin miedo y sin tacha, si acaso con un pequeño defecto que a la larga se convierte en un defecto/virtud, un defecto reversible, dice, como la audacia o la timidez. Para Ortega, en cambio, el héroe, con una orientación más precisa, es el hombre decidido a no contentarse con la realidad, a no repetir los gestos de los que le han precedido, porque quiere ser uno mismo, y asentar en sí

\footnotetext{
${ }^{52}$ M. Delibes (1994), p. 307.

${ }^{53}$ M. Delibes (1991), p. 132-133.

${ }^{54}$ J. Marías (1997), p. 164.

${ }^{55}$ R. F. del Valle Spinka (1975), pp. 17-18.

${ }^{56}$ M. Delibes (1994), p. 106.
} 
mismo sus $\operatorname{actos}^{57}$. Es el asceta: el que tiene una vida llena de ejercicios y privaciones, porque se exige más que a los demás. Escribe en «Azorín: primores de lo vulgar», en 1917: «Lo heroico de todo héroe radica siempre en el esfuerzo sobrenatural para resistirse al hábito. La acción heroica es, en todo caso, una aspiración a innovar la vida, a enriquecerla con una nueva manera de obrar. Heró́smo es rompimiento con la tradición, con lo habitual, con la costumbre. El héroe no tiene costumbres; su vida entera es una invención constante» ${ }^{58}$. Porque la premisa de Ortega es que la vida es un naufragio. Pero naufragar no es ahogarse, sino agitar los brazos para salvarse, manteniéndose a flote: la conciencia necesaria para poder ser creativo, en las artes o en la vida, con esa voluntad de aventura de la que habla. Con ese carácter programático, proyectivo, del hombre futurizo del que escribe Marías: instalado, con la anticipación del futuro en el presente y la retención en el presente del pasado: pasando de un equilibrio a otro en el fluir de la vida, hasta que en un determinado momento pueda quedar afectada por una radical desorientación: Lo que le sucede a Sebastián, que funciona como el antihéroe de Delibes, pero que se revela (como pivote de la trama de Aún es de día) con los rasgos entresacados del héroe de Ortega y Gasset. Con un movimiento que en él es dialéctico, con un recorrido vital hecho de enfrentamientos, siempre inseguro de sí mismo ${ }^{59}$, pero firme en su voluntad de seguir dando pasos. Hasta ese punto álgido en que se reencuentra con su fe aletargada, con la que se siente capaz de imponer (de imponerse) sus propias decisiones, y resistir, por primera vez, un embate que le llega de fuera: «De súbito, notaba una oleada de vigor que hacía de él, por una vez, un ser autónomo e independiente» ${ }^{60}$; y al final de la novela, con su respuesta heroica, al decidir salvar a Aurora, casándose con ella, frente a la tentación de evadirse del mundo dentro de los muros del convento. Dijo Ortega que todos llevamos dentro como el muñón de un héroe ${ }^{61}$. Sebastián también: Ese muñón es lo que queda de día, con el título definitivo (que tampoco convenció a Delibes) que exagera el desenlace tímidamente optimista de la novela. Pero que no puede obviar que todo muñón exige, previamente, una amputación.

\section{Obras citadas}

Alonso De los Ríos, César: Conversaciones con Miguel Delibes, Barcelona, Destino, 1993.

\footnotetext{
57 J. Ortega y Gasset (1950), pp. 389-390.

58 J. Ortega y Gasset (1983), pp. 177-178.

${ }^{59}$ M. Delibes (1994), p. 116. Escribe: «Esa desconfianza en las propias fuerzas caracterizó a Sebastián desde que dispuso de la facultad del raciocinio.»

${ }^{60}$ M. Delibes (1994), p. 237.

${ }^{61}$ J. Ortega y Gasset (1950), p. 394.
} 
AyAlA, Francisco: Tragicomedia de un hombre sin espiritu, Narrativa completa, Madrid, Alianza Editorial, 1993.

CELA, Camilo José: La familia de Pascual Duarte, Barcelona, Seix-Barral, 1983.

DELIBES, Miguel: Aún es de día, Barcelona, Destino, 1994.

DELIBES, Miguel: España 1936-1950: Muerte y resurrección de la novela, Barcelona, Destino, 2004.

DeliBeS, Miguel: La censura de prensa en los años 40 (y otros ensayos), Valladolid, Ámbito, 1985.

DelibeS, Miguel: Pegar la hebra, Barcelona, Destino, 1991.

Delibes, Miguel y Vergés, Josep: Correspondencia, 1948-1986, Barcelona, Destino, 2002.

GRACIA, Jordi: Estado y cultura. El despertar de una conciencia crítica bajo el franquismo, 1940-1962, Barcelona, Anagrama, 2006.

KUNDERA, Milan: El arte de la novela, Barcelona, Tusquets, 1987.

LAFORET, Carmen: Nada, Barcelona, Espasa Calpe, 2007.

MARCEL, Gabriel: El misterio del ser, Barcelona, Edhasa, 1971.

MARÍAS, Julián: Antropología metafisica, Madrid, Revista de Occidente, 1970.

MARÍAS, Julián: La escuela de Madrid, Buenos Aires, Emecé, 1959.

MARÍAS, Julián: Persona, Madrid, Alianza, 1997.

ORTEGA Y GASSET, José: Azorin: primores de lo vulgar, Obras completas, tomo II, Madrid, Alianza Editorial, 1983.

ORTEGA Y GASSET, José: Meditaciones del Quijote, Obras completas, tomo I, Madrid, Alianza Editorial, 1950.

Puente SAmANiEgo, Pilar de la: Castilla en Miguel Delibes, Salamanca, Editorial Universidad de Salamanca, 1986.

RoDRíGUEZ, Jesús: El sentimiento del miedo en la obra de Miguel Delibes, Madrid, Pliegos, 1989.

Valle SpinKA, Ramona F. del: La conciencia social de Miguel Delibes, Nueva York, Torres Library of Literary Studies, 1975. 